\title{
OTOMATISASI PENGERINGAN IKAN MENGGUNAKAN WEATHER STATION BERBASIS IOT PADA KOPERASI KARYAWAN BANK BTN REGIONAL CABANG TANGERANG
}

\author{
Muhamad Dwi Aprianto ${ }^{1}$ \\ Muhamad Muhandika ${ }^{2}$ \\ Ahmad Hidayat ${ }^{3}$ \\ E-mail : $\underline{\text { md.apriyanto@ @aharja.info }}{ }^{1)}$ muhandika@ raharja.info ${ }^{2)}, \underline{\text { ahmadhidayat@ } @ \text { raharja.info }^{3)}}$
}

\begin{abstract}
ABSTRAK
Perkembangan dan penggunaan teknologi computer saat ini bukan hal yang asing bagi dunia pendidikan. Karena dalam dunia pendidikan computer merupakan alat atau akses yang sangat penting dalam menunjang majunya dunia pendidikan, sehingga dapat memperlancar tugas atau kegiatan instansi yang terkait dalam dunia pendidikan tersebut. Penggunaan computer sangat penting dalam memperlancar atau mempermudah dalam proses pengajaran, Pengolahan Data, Membuat soal Ujian, Penyimpanan data-data yang penting bahkan sebagai bahan pendidikan itu sendiri, tanpa ada penggunaaan komputer yang mempermudah dalam mengakses segala bentuk data mungkin dunia pendidikan yang ada belum semaju dan berkembang seperti sekarang ini. Membuat alat pendeteksi cuaca sebuah produk yang nantinya akan dijadikan sebagai pendeteksi cuaca pada Koperasi Karyawan BANK BTN Regional Cabang Tangerang.
\end{abstract}

Kata Kunci: computer, teknologi, cuaca.

\begin{abstract}
The development and use of computer technology is currently not a stranger to the world of education. Because in the world of computer education is the tool or access that is essential in supporting advances in the world of education, so as to streamline tasks or activities of the agencies related to education. The use of computer is essential in the smooth or ease into the process of teaching, Data processing, making the exam questions, data storage-data that matters even as education itself, without any ideas of a computer that makes it easy to access any data existing education world may yet semaju and developed as it is today. Make a weather product detection tool that would later serve as a weather detection on Cooperative BANK BTN Employees Regional Branch Tangerang.
\end{abstract}

Keywords: computer, technology, weather. 


\section{PENDAHULUAN}

Alat pendeteksi cuaca dengan mikrokontroler dan juga pengeringan ikan secara otomatis tanpa ada nelayan yang siaga menjaganya. Mikrokontroler merupakan sebuah chip atau IC (Integrated Circuit) yang dapat diprogram menggunakan komputer. Tujuan menanamkan program pada mikrokontroler adalah agar rangkaian elektronik dapat membaca input, memproses input tersebut dan kemudian menghasilkan output sesuai yang diinginkan. Jadi mikrokontroler bertugas sebagai 'otak' yang mengendalikan input, proses dan output sebuah rangkaian elektronik. Mikrokontroler tidak sama dengan mikroprosesor, mikroprosesor adalah sebuah chip CPU yang digunakan oleh sistem komputer, sedangkan mikrokontroler adalah merupakan sebuah chip sistem komputer itu sendiri.

\section{RUMUSAN MASALAH}

Berdasarkan hasil wawancara pada BANK BTN Regional Cabang Tangerang, Sistem alat yang bekerja pada saat ini masih belum ada. Maka saya berinisiatif inin membuat alat pendeteksi cuaca dan pengerringan ikan untuk BANK BTN Regional Cabang Tangerang juga berguna untuk masyarakat. alat pendeteksi cuaca ini membutuhkan perangkat diantaranya adalah Wemos, DHT11, LDR (Sensor Cahaya), Module Relay, Sensor Hujan dan Liquid Crystal Display (LCD). Wemos yaitu kit elektronik atau papan rangkaian elektronik open-source yang di dalamnya terdapat komponen utama yaitu sebuah chip mikrokontroller dengan sensor DHT11, Sensor Hujan, Module Relay. Sedangkan sensor photo resistor (LDR) yaitu komponen elektronika yang memiliki fungsi untuk menerima cahaya. Sebagai tampilan suhu menggunakan Liquid Crystal Display (LCD). Untuk sistem operasi yang digunakan pada pendeteksi cuaca menggunakan sistem Arduino IDE. Arduino IDE menyediakan platform terbuka bagi para pengembang untuk menciptakan aplikasi yang digunakan oleh bermacam piranti bergerak.

\section{LITERATUR RIVIEW}

1. Penelitian yang dilakukan oleh Mashaler Suradam, Rifki Reinaldo, Eko Andri, Iwan Sugihartono dari Universitas Negeri Jakarta FMIPA jurusan Fisika tahun 2013, yang berjudul "Perancangan Sistem Telemetri Akuisisi Data Cuaca Dengan XBee Pro-S2" merupakan perangkat instrument yang berfungsi untuk mengukur variable-variabel cuaca secara real time seperti temperatur, tekan dan kelembaban menggunakan modul antena XBee Pro S2B.

2. Penelitian yang dilakukan oleh Ellis Naria Pakpahan dari Universitas Sumatera Utara FMIPA departemen Fisika tahun 2010, yang berjudul "Prototipe Stasiun Cuaca Mini Berbasis Mikrokontroler ATmega8535" perancangan alat pemonitoring cuaca yang memantau parameter-parameter seperti suhu, kelembaban dan kecepatan angin menggunakan mikrokontroler ATmega 8535dan sistem penampil data menggunakan Visual Basic.

3. Penelitian yang dilakukan oleh Heri Susanto, Rozeff Pramana, ST. MT., Muhamamad Mujahidin, ST. MT. dari Universitas Maritim Raja Ali Haji FT jurusan Teknik Elektro tahun 2013, yang berjudul "Perancangan Sistem Telemetri Wireless untuk Mengukur Suhu dan Kelembaban Berbasis Arduino Uno R3 ATmega328p dan XBee Pro" penelitian ini merancang sistem telemetri wireless yang dapat mengukur suhu dan kelembaban dengan desain portable yang dilengkapi perekam data, outputnya dapat ditampilkan melalui LCD.

4. Menurut Sofyan (2015) dalam jurnal nasional yang berjudul "Manipulasi Suhu Pada Pengeringan Ikan Teri Tenaga Surya Menggunakan Mikrokontroller ATmega 2560" penelitian ini merancang tentang pengeringan ikan teri dengan sinar matahari untuk mengurangi penggunaan listrik agar lebih cepat dan higienis pada nelayan.

5. Menurut Sigurjón Arason (2003) dalam jurnal internasional yang berjudul "The drying of fish and utilization of geothermal energy" Penelitian ini terutama difokuskan pada penggunaan energi panas bumi di daerah dengan panas rendah.

6. Menurut Dwi Marpuah (2010) dalam jurnal nasional yang berjudul "Pembuatan Prototipe Alat Pengering Pakaian Berbasis Mikrokontroller AT89S51" Memanfaatkan 
mikrokontroler AT89S51 sebagai pengendali seluruh rangkaian, SHT11 sebagai pendeteksi suhu dan kelembaban ruangan dan hasilnya dapat dilihat melalui tampilan LCD 16x2.

\section{PEMECAHAN MASALAH}

Setelah mengamati dan meneliti dari beberapa permasalahan yang terjadi, terdapat beberapa alternatif pemecahan dari permasalahan yang dihadapi yaitu, dengan menggunakan Arduino Uno. Bisa dikendalikan dimana saja, bisa menggunakan smartphone untuk mengendalikan pendeteksi cuaca.

\section{IMPLEMENTASI}

\section{Prosedur Motor DC}

Pada uji coba yang dilakukan motor de adalah untuk mengontrol gerak yang dihasilkan. Dengan melalui proses menyambungkan pin dari driver disambungkan ke pin pada arduino mega 328. Kemudian melakukan pemograman untuk mengatur pengujian kcepatan pada motor dc. Berikut ini adalah skema pada motor dc.

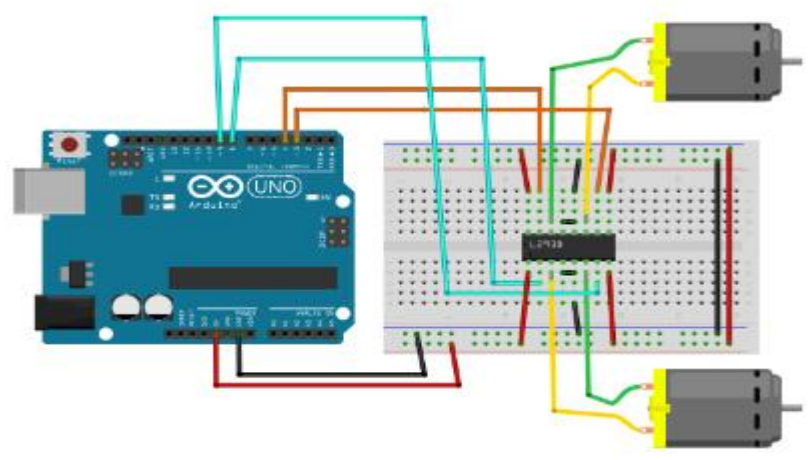

\section{fritzing}

Gambar 1. Skema relay dan motor dc

Prinsip kerja pada rangkaian motor dc diatas adalah ketika pada saat terang atau tidak ada air maka motor dc akan bergerak keluar, sedangkan pada saat hujan (ada air) atau tidak ada cahaya (gelap) makan motor dc akan masuk kedalam.

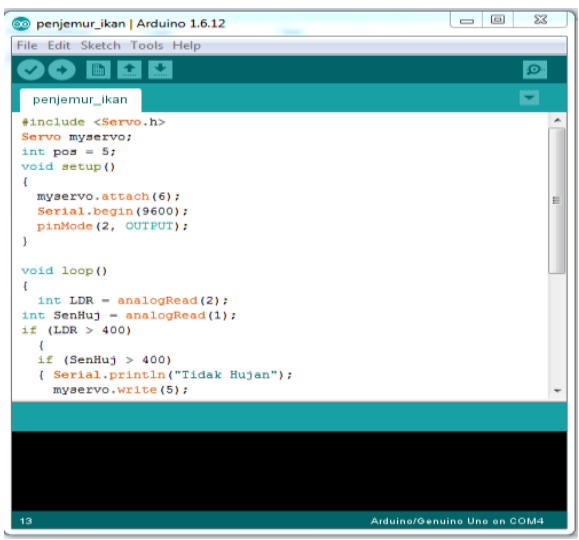

Gambar 2. List program pengering ikan otomatis

\section{Rangkaian Keseluruhan}

Rangkaian skematik keseluruhan yang tergabung dari beberapa komponen seperti power supply, sensor dht11, lcd, sensor hujan dan sensor cahaya. 


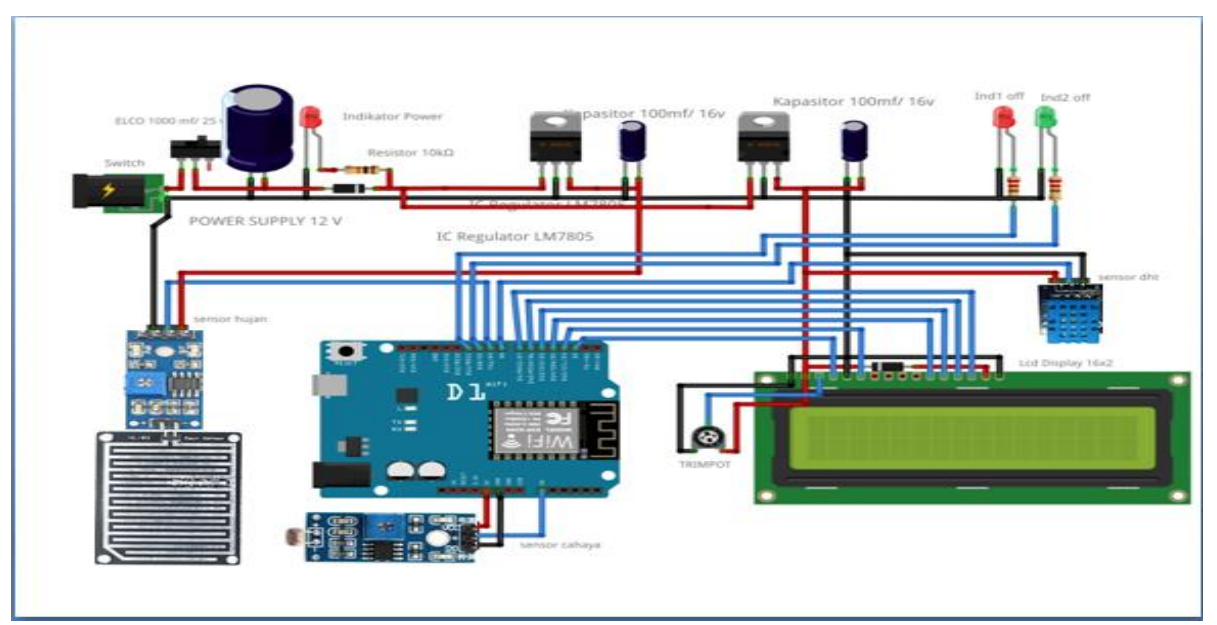

Gambar 3. Rangkaian skemati keseluruhan

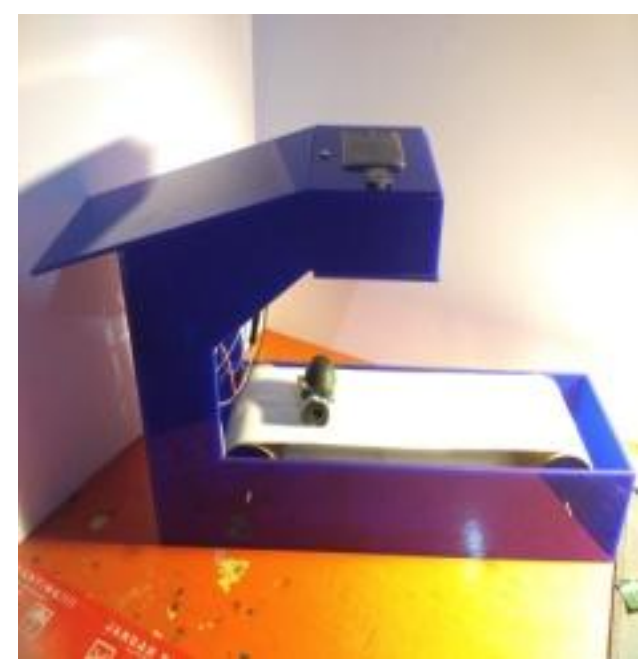

Gambar 4. Prototype keseluruhan

\section{Source Code Program Yang Di Gunakan}

Source code program yang di gunakan pada alat pendeteksi cuaca dan pengering ikan otomatis.
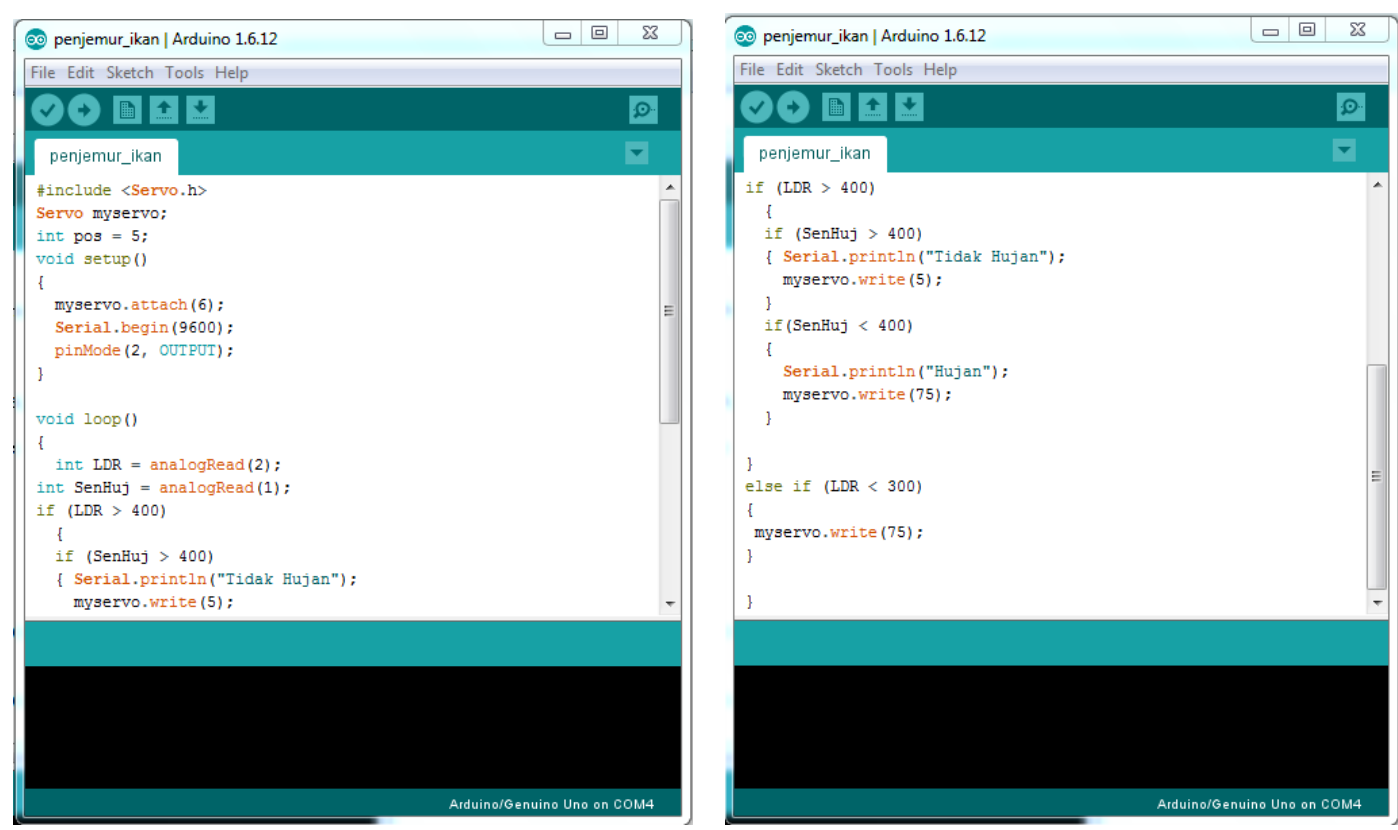

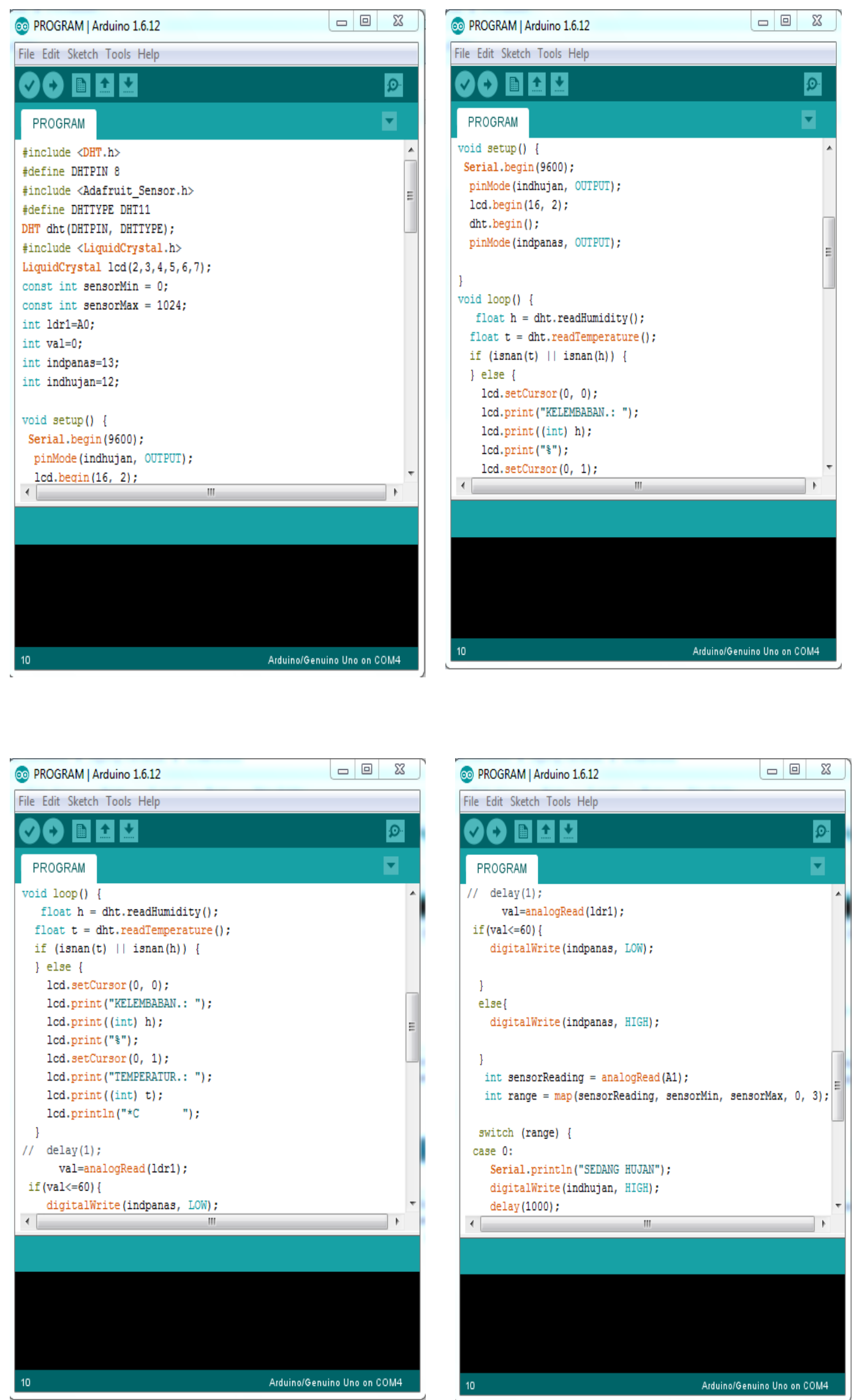


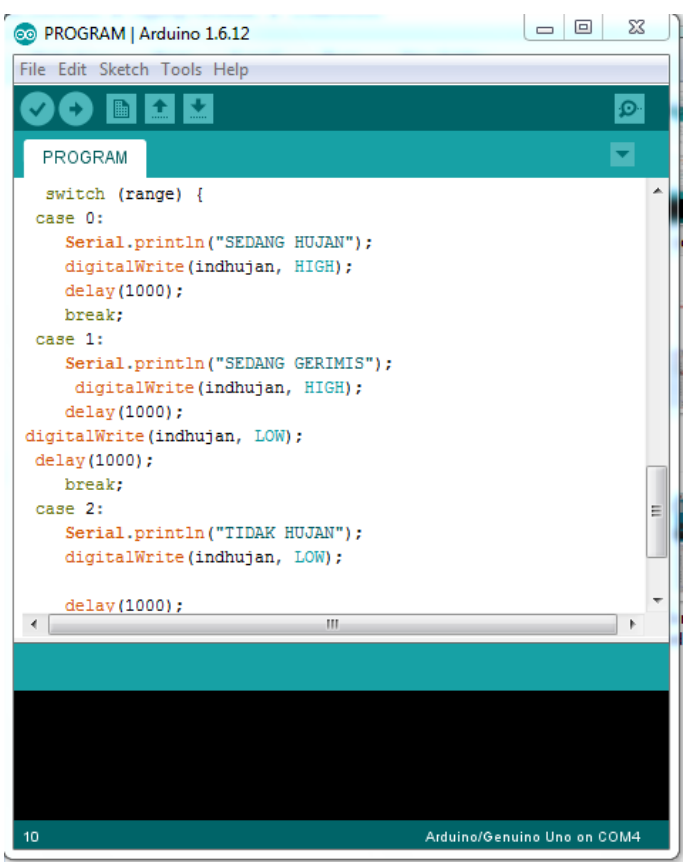

Gambar 5. Source code program keseluruhan

\section{KESIMPULAN}

Cara untuk mengetahui cuaca dan pengeringan ikan secara otomatis yaitu dengan meletakkan alat disekitar area pesisir pantai (pendeteksi cuaca) dan persegi panjang (pengering ikan otomatis) yang nantinya dapat dilihat melalui smartphone. Dengan adanya alat pendeteksi cuaca pegawai hanya perlu mengetahui cuaca disekitar area pesisir pantai melalui smartphone dan untuk para nelayan hanya perlu meletakkan ikan yang akan dikeringkan pada alat tersebut karena sudah dirancang dengan sistem otomatisasi tanpa harus memindahkan ikan yang sedang dikeringkan ke tempat lain.

\section{DAFTAR PUSTAKA}

1. Adelia dan Jimmy Setiawan. 2011. Implementasi Customer Relationship Management (CRM) pada Sistem Reservasi Hotel berbasisi Website dan Desktop. Jurnal Sistem Informasi Vol. 6 No. 2, September 2011.

2. Arason, Sigurjón. 2013. "The drying of fish and utilization of geothermal energy".

3. Archarya,Shivani. Pandya, Vidhi. 2013. "Bridge between Black Box and White Box Gray Box Testing Technique" Internasional Journal of Electronics and Computer Science Engineering ISSN- 2277-1956 Volume 2 No.1

4. Iswandi, Eka. 2015. Sistem Penunjang Keputusan Untuk Menentukan Penerimaan Dana Santunan Sosial Anak Nagari Dan Penyalurannya Bagi Mahasiswa Dan Pelajar Kurang Mampu Di Kenagarian Barung - Barung Balantai Timur. Jurnal tekno Vol 3, No 2. Hal 7079. Oktober 2015.

5. Joni, I Made. Budi Raharjo. 2011. Pemrograman C dan Implementasi. Informatika Bandung.

6. Khana, Ika Nur. 2013. WirelessMon, Very Handle to Capturing your WiFi Network Access.

7. Marpuah, Dwi. 2010. "Pembuatan Prototipe Alat Pengering Pakaian Berbasis Mikrokontroller AT89S51". 
8. Nikolaos Bourbakis, Konstantina S. Nikita and Ming Yang. 2013. International Journal of Monitoring and Surveillance Technology Resarch. Vol 1:2, ISSN: 2166-7241, EISSN: 2166-725X. IGI PA, USA.

9. Sutarman. 2012. "Buku Pengantar Teknologi Informasi". Jakarta: Bumi Aksara.

10. Sutabri, Tata. 2012. Konsep Sistem Informasi. Yogyakarta: Andi Offset.

11. Sutabri, Tata. 2012. Konsep Dasar Informasi. Yogyakarta: Andi Offset.

12. Syahrul. 2014. "Pemrograman Mikrokontroler AVR Bahasa Assembly dan C". Bandung: Informatika.) 